\title{
Relation between Health Literacy and Health Promoting Behaviors among Elderly at Tanta City
}

${ }^{1}$ Nadia Ismail Elsaeid Aldosokey. ${ }^{2}$ Ikbal Fathalla Elshafeai, ${ }^{3}$ Nahla Said Mahmoud and ${ }^{4}$ Lulah Abdelwahab Abdelatey Hassan.

\author{
${ }^{1}$ Demenistrator, Community Health Nursing Department, Faculty of Nursing, Tanta \\ University, Egypt. \\ ${ }^{2}$ Community Health Nursing Department, Faculty of Nursing, Tanta University, Egypt. \\ ${ }^{3}$ Lecturer, Community Health Nursing Department, Faculty of Nursing, Tanta University, \\ Egypt. \\ ${ }^{4}$ Assistant Professor of Community Health Nursing Department, Faculty of Nursing, Tanta \\ University, Egypt.
}

\begin{abstract}
Health literacy is an emerging concept in the health care environment. It is one of the main factors that is related to adoption of the healthy lifestyle behaviors. Low health literacy in older adults leads to poor overall health. The aim of the study: was to assess the relation between health literacy and health promoting behaviors among elderly at Tanta city. Study design: A descriptive correlational study design was used in this study. Study settings: This study was conducted at the outpatient clinics of health insurance hospital at Tanta city. Study subjects: A convenience sample of 400 elderly who attend the previous setting was included in the study. Study tool: A structured interview schedule was used to collect data in this study which consisted of four parts: Part I: Socio-demographic characteristics and medical history of the elderly. Part II: Assessment of health literacy for the elderly. Part III: The Health Promotion Lifestyle Profile II (HPLP-II). Part IV: Assessment of the elderly knowledge about the basic health information. Results: about two thirds of the studied elderly had poor level of health literacy while more than half of the studied elderly had moderate level of adherence to health promoting behaviors. In addition, there was significant positive correlation between total health literacy scores, total knowledge scores, and total health promotion behaviors scores $(\mathrm{P}<0.005)$.Conclusion: Poor health literacy level was associated with low adherence to the healthy lifestyle among the studied elderly. Therefore, the community health nurse should organize health education programs about health promoting lifestyles and health literacy for older adults to help in improving their overall health.
\end{abstract}

Key wards: Health literacy ,Promoting behaviors, Elderly. 


\section{Introduction}

Recently, there has been massive increase in the number of the older adult worldwide. According to World Health organization (WHO) the proportion of the world's population over 60 years will nearly double from $12 \%$ to $22 \%$ between 2015 and $2050^{(\mathbf{1})}$. In Egypt, the Central Agency for Public Mobilization and Statistics (CAPMAS) stated that, the number of older persons who are 60 years and over reached 6.410 million in 2018, which represents $6.7 \%$ of total population. It is expected to reach $20.8 \%$ in $2050^{(2)}$. Therefore, there is an urgent demand to increase attention in supporting the health and well-being of the elderly ${ }^{(3-5)}$. Unfortunately, many disabilities and diseases are suffered by older people. These diseases are more common among older people such as diabetes mellitus, hypertension, heart disease, osteoporosis and the risk of developing them increases as the people grow older ${ }^{(6,7)}$.

Elderly engagement in health promotion activities, choosing healthy behaviors, and making changes in their lifestyle this will reduce the risk of developing chronic diseases and disabilities. So, it is particularly important for older persons to adopt a healthy lifestyle practices that minimize their risk of death from morbidity and maximize their healthful aging ${ }^{(8)}$.The earlier adoption of those good habits, the greater the benefit in older age. According to the World Health Organization (WHO), it is not too late to change risky behaviors among elderly to promote their health ${ }^{(9)}$.

One of the main factors that can be related to adoption of healthy lifestyle behaviors is the health literacy. The health literacy concept is recently appeared in the health care environment in the early to mid1990s. It refers to the capacity and ability to obtain, process, and understand healthcare information to make proper decisions about health ${ }^{(\mathbf{1 0})}$. The individual's health literacy abilities vary greatly and can be viewed on a continuum ranging from adequate to marginal to inadequate. Many studies had demonstrated that the older adults are at risk of inadequate or marginal health literacy due to different age-related changes such as decline in physical and mental health status as changes in cognition and sensory impairments as lack of vision that lead to lack of use of reading skills and inability to complete complex cognitive tasks, especially those that require effortful processing of information ${ }^{(\mathbf{1 1}, \mathbf{1 2})}$. So, older adults carry the biggest burden because of inadequate health literacy, which is shown as an unfavorable outcome to their health such as lack of knowledge of the health promoting behaviors, underutilization of preventive health service such as 
vaccinations and mammograms and high morbidity rates ${ }^{(\mathbf{1 3}, \mathbf{1 4})}$.

Older adults are more susceptible to poor health, as the level of health literacy constantly decreases with advanced age. It is probable that the older adults carry the biggest burden because of an inadequate health literacy, which shows itself as an outcome that is unfavorable to an old person's health [7]. Health literacy of older adults is inuenced also by basic socioeconomic factors [3

Moreover, the elderly people need some advanced skills of health literacy such as reading, writing, listening, speaking, numeracy, critical analysis , communication and interaction skills to help themselves to participate optimally in healthcare. The adequate health literacy is associated with disease acceptance, adequate understanding about self-care, self-efficiency in disease management, adherence to treatment, self-management and the outcome of more ideal health ${ }^{(10,11,14)}$. Community health nurse plays an important role in improving the health literacy skills among the elderly to enhance their commitment to the health promoting behaviors. This can be done through inspiring the older adults to change their behavioral habits and unhealthy lifestyle. This could be done through the choice of suitable medical education techniques. So, they can recognize how their lifestyle influences their health and what risk factors they may face. The nurse will help them to know how to keep, strengthen and achieve optimum health, and in the case of an illness, elderly will know how to effectively navigate the health system ${ }^{(\mathbf{1 2}, 13)}$. There are few studies that were done regarding heath literacy particularly among elderly in Egypt. Therefore, this study was conducted to assess the relationship between health literacy among the elderly and their health promoting behaviors.

\section{Aim of the Study}

The aim of the study was to assess the relation between health literacy and health promoting behaviors of elderly at Tanta city.

\section{Research Question}

What is the relation between health literacy and health promoting behaviors of elderly at Tanta city?

\section{Subjects and method}

\section{Subjects}

\section{Study design}

A descriptive correlational study design was used in this study.

\section{Study Setting}

This study was conducted at the outpatient clinics of health insurance hospital for elderly at Tanta city.

\section{Subjects}

A convenience sample of 400 elderly patients who attend the previous setting was included in the study. 


\section{The inclusion criteria for elderly}

- Free from psychiatric disorders.

- Able to communicate and accept to participate in the study.

The sample size was calculated using EpiInfo software statistical package created by World Health organization and Center for Disease Control and Prevention, Atlanta, Georgia, USA version $2002^{(15)}$. The sample size was estimated with test of power analysis (95\% confidence limit, $80 \%$ power of the study). It was calculated to be not less than 384 elderly and the sample size was increased to 400 elderly.

\section{Tool of data collection}

In order to collect the necessary data, a structured interview schedule was used in this study which consisted of four parts as follows:

\section{Part I: Socio-demographic} characteristics and medical history of the elderly

This part included data about sociodemographic characteristics and medical history. The socio-demographic characteristics data included age, sex, marital status, level of education, previous occupation, family income and place of residence. The medical history data included the presence of chronic diseases, duration of illness, medication taken, number of medications taken daily, number of previous hospital admission and smoking and its duration.

\section{Part II: Assessment of health literacy for the elderly}

This part was developed by the researcher based on the related health literacy scales (16-19). It included 34 statements that covered the following items: access to health information (6 statements), reading of health information (6 statements), understanding the health information (8 statements), appraisal of health care (5 statements), use of health services (4statements) and communication with health care providers (5statements).

\section{Scoring system}

- Each statement was rated using 5 points rating scale for each item, ranged from 1 (never), 2 (rarely), 3 (sometimes), 4 (often), and 5 (always).

- The overall score was classified into:

- (Poor health literacy) $<50 \%$ of total score.

- (Fair health literacy) $50 \%$ - $<70 \%$ of total score.

- $\quad($ Good health literacy $) \geq 70 \%$ of total score.

Part III: The Health Promotion Lifestyle Profile II (HPLP-II) ${ }^{(20)}$

This part assessed the health promoting lifestyle. The researcher adapted the Health Promotion Lifestyle Profile II 
(HPLP-II) that was designed by Walker et al., 1995 based on Pender's health promotion model to measure health promoting lifestyle behaviors (HPBs). It included 42 statments which encompassed six healthy lifestyle dimensions: Health responsibility (11 statements), physical activity (3 statements), nutrition (10 statements), interpersonal relations (6statements) rest \& stress management (5 statements) and spiritual growth (7 statements).

\section{Scoring system}

- Each statement was rated using 4 points rating scale, ranged from 1 (never), 2 (sometimes), 3 (often), and 4 (always).

- The overall score was classified as follows:

- (Low level of adherence to health promoting behaviors) $<50 \%$ of total score.

- (Moderate level of adherence to health promoting behaviors) $50 \%-<$ $75 \%$ of total score.

- (High level of adherence to health promoting behaviors) $75 \%-100 \%$ of total score.

Part IV: Assessment of the elderly knowledge about the basic health information

This part was developed by the researcher to assess the elderly knowledge about the basic health information such as the normal body temperature, normal pulse rate, normal level of blood pressure, normal blood glucose level, complications of diabetes mellitus, complications of hypertension, risks of obesity and the causes of osteoporosis.

\section{Scoring system}

The items of the questionnaire were checked with a model answer which was prepared by the researcher. Each correct and complete answer was given score 2, correct and incomplete answers given score 1 while don't know was given score zero. Then all the correct answers were summed up. The total score of knowledge was 16 and classified into:

- (Poor knowledge) $<50 \%$ of total score indicated.

- (Fair knowledge) 50- < 70\% of total score.

- $\quad($ Good knowledge $) \geq 70$ of total score.

\section{Method}

\section{The study was carried out as follows:}

- Administrative approval:

- An official letter to conduct the study was obtained from the Dean of the Faculty of Nursing and directed to the manager of outpatient clinics of Health Insurance Hospital.

- The manager of outpatient clinics of Health Insurance Hospital was informed about the objectives of the study to take his permission to collect the data from the previous setting. 
- Ethical and legal consideration:

- The consent of the Faculty's Ethical Committee was obtained to conduct the study.

- An informed consent was obtained from all study subjects after providing appropriate explanation about the purpose of the study.

- Each participant was informed that he/she has the right to withdraw from the study any time he/she wants.

- Anonymity was considered.

- Nature of the study didn't cause any harm or pain for the entire subjects.

- Confidentiality and privacy was considered regarding the collected data.

\section{- Developing the tool:}

- Part I, II and IV of the study tool was developed by the researcher based on literature review.

- Part III of the study tool was adapted, modified and translated into Arabic language by the researcher.

- The study tool was tested for face and content validity by jury of five professors expertise in the field of Community Health Nursing before conducting the study.

- The study tool was tested for its reliability using Chronabach's alpha test. It was found to be $(0.843)$ for the entire study tool while the reliability of part II which assessed the health literacy was (0.905).The reliability of part III which assessed the adherence to health promoting behaviors was (0.787) and the reliability of part IV which assessed the elderly knowledge about basic health information was (0.800).

\section{- $\quad$ The pilot study}

- A pilot study was carried out by the researcher on 40 elderly for testing the tool for its clarity, applicability and to identify obstacles that may be encountered with the researcher during data collection. Accordingly, the necessary modification/s was done. Those elderly were excluded from the study subjects.

\section{- The actual study}

- The researcher met the elderly patients in the waiting area of the outpatient clinics of the health insurance hospital.

- The structured interview was individually administered with each elderly at the outpatient clinics of the health insurance hospital.

- The average time spent for collecting the data from each elderly was $10-15$ minutes.

- The data was collected by the researcher over a period of five months starting from October 2019 to March 2020. 


\section{- Statistical analysis of data}

The collected data was organized, tabulated and statistically analyzed using SPSS (statistical package of social science) version 23. For quantitative data, the range, mean and standard deviation were calculated. For qualitative data, which describe a categorical set of data by frequency, percentage or proportion of each category, comparison between two groups and more was done using Chisquare test $\left(\chi^{2}\right)$. Correlation between variables was evaluated using Pearson's correlation coefficient (r). Significance was adopted at $\mathrm{p}<0.05$ for interpretation of results of tests of significance ${ }^{(21)}$.

\section{Results}

Table (1) represents the distribution of the studied elderly patients according to their socio-demographic characteristics. The table shows that, the age of the studied elderly ranged from 60-90 years with a mean age $64.45 \pm 5.37$ years, and more than two -thirds $(68.5 \%)$ of them their age ranged from $60-<65$ years old. More than half $(56.2 \%)$ of them were females and $53.9 \%$ of them were married. As regard to education, $50.1 \%$ of the studied elderly were illiterates and read and write and $31.3 \%$ had secondary education. About three quarters $(73.3 \%)$ of the studied elderly were working before retirement, and $29.4 \%$ of them were farmers. Regarding their family income, $79.0 \%$ of the elderly reported that their income was sufficient for their needs while only $14.7 \%$ of them mentioned that, their income wasn't sufficient and owed. In relation to residence, $50.2 \%$ of the studied elderly were living in rural areas.

Table (2) represents the distribution of studied elderly patients according to their medical history. The table illustrates that, the majority $(96.5 \%)$ of the studied elderly were suffering from chronic diseases. It also shows that, nearly half $(50.5 \%$ and $47.7 \%$ ) of them were suffering from diabetes mellitus (DM) and hypertension respectively with a mean duration $(9.68 \pm 5.93$ and $8.72 \pm 6.23$ years respectively). Slightly more than one third $(34.7 \%)$ of them were suffering from osteoarthritis with a mean duration (13.13 \pm 7.83 years). Moreover, $13.5 \%$, $15.5 \%$ and $6.2 \%$ were suffering from heart diseases, liver disease and osteoporosis respectively. It also showed that, $60.1 \%$ of them were taking their medication (1-4) times per day.

Regarding previous hospital admission, more than three quarters $(78.5 \%)$ of the studied elderly were admitted to the hospital, About two thirds (65.3\%) of them were admitted to the hospital $1-<5$ times while $34.7 \%$ of them had been admitted to the hospital $\geq 5$ times. Concerning smoking, slightly less than three quarters 
$(71.3 \%)$ of the studied elderly weren't smokers.

Table (3) represents the distribution of the studied elderly according to their response to health literacy categories. The table illustrates that, about two thirds $(61.5 \%$ and $63.4 \%$ ) of the studied elderly reported that, they never/rarely access to health information and reading of the health information respectively, more than half $(55.4 \%)$ of the studied elderly reported that they often /always could communicate with health care providers and $40.8 \%$ always understand health information. Moreover, $37.0 \%$ of them often or always use health services and $23.4 \%$ often or always able to read the health information.

Figure (1): represents the distribution of the studied elderly according to their total health literacy level. The figure illustrates that, $61.0 \%$ of the studied elderly had poor level of health literacy, slightly more than one quarter $(27.3 \%)$ of them had fair level of health literacy while only $11.8 \%$ of them had good level of health literacy.

Table (4) represents the distribution of the studied elderly according to their level of adherence to health promoting behaviors' dimensions. The table shows that, less than two thirds $(61.7 \%)$ of the studied elderly had low adherence level toward their health responsibility while the majority $(91.7 \%)$ of them had low adherence level to physical activity. Moreover, $65.5 \%$ of them had moderate adherence level toward their proper nutrition. In addition, about $46.0 \%$ of them had moderate level of adherence toward their interpersonal relations. Concerning rest and stress management dimension, more than half (57.5\%) of the studied elderly had low adherence level. Regarding their spiritual growth, more than two thirds $(68.0 \%)$ of them had moderate adherence level.

Figure (2) represents the distribution of the studied elderly according to their total level of adherence to health promoting behaviors' dimensions. The figure shows that, more than half $(59.5 \%)$ of the studied elderly had moderate level of adherence to health promoting behaviors, more than one-third $(37.0 \%)$ of them had low adherence level while only $3.5 \%$ of them had high adherence level.

Figure (3): represents the distribution of the studied elderly according to their total knowledge level regarding basic health issues. The figure illustrates that, more than half $(52.3 \%)$ of the studied elderly had poor knowledge level regarding basic health issues, more than one-third $(36.0 \%)$ of the studied elderly had fair level of knowledge while only $11.8 \%$ had good level.

Table (5) represents the relationship between total knowledge level and both total health literacy level and total adherence to health promoting behaviors 
level among the studied elderly patients.

The table shows that, there was statistical significant relationship between total knowledge level among the studied elderly patients and their level of total health literacy $(\mathrm{p}=0.0001)$ where $59.5 \%$ of those who gained good level of total knowledge gained also good level of total health literacy. It also shows that, there was statistical significant relationship between total knowledge level among the studied elderly patients and their level of total adherence to health promoting behaviors $(\mathrm{p}=0.0001)$ where those who gained good level of total knowledge were from those who gained either moderate or high level of total adherence to health promoting behaviors.

Table (6) represents relationship between total health literacy level and level of total adherence to health promoting behaviors among the studied elderly patients. The table shows that, slightly more than half $(50.4 \%)$ of the studied elderly who had poor level of health literacy had low adherence to health promoting behaviors. It also revealed that, more than three quarters $(76.1 \%)$ of those who had fair level of health literacy also had moderate level of adherence to health promoting behaviors. Moreover, about one quarter (25.5\%) of the studied elderly who had good level of health literacy also had high adherence level to health promoting behaviors. There was statistically significant relationship between total health literacy levels and levels of total adherence to health promoting behaviors among the studied elderly patients $(\mathrm{p}=0.0001)$. 
Table (1): Distribution of the studied elderly according to their socio-demographic characteristics

\begin{tabular}{|c|c|c|}
\hline \multirow[t]{2}{*}{ Socio-demographic data } & \multicolumn{2}{|c|}{$\begin{array}{l}\text { The studied elderly patients } \\
\qquad(\mathrm{n}=400)\end{array}$} \\
\hline & $\mathbf{n}$ & $\%$ \\
\hline $\begin{array}{l}\text {-Age years: } \\
60-<65 \\
65-<70 \\
70-<75 \\
75-\leq 90\end{array}$ & $\begin{array}{c}274 \\
62 \\
52 \\
12\end{array}$ & $\begin{array}{c}68.5 \\
15.5 \\
13.0 \\
3.0\end{array}$ \\
\hline $\begin{array}{l}\text { Range } \\
\text { Mean } \pm \text { SD }\end{array}$ & \multicolumn{2}{|c|}{$\begin{array}{c}60-90 \\
64.45 \pm 5.37 \\
\end{array}$} \\
\hline $\begin{array}{l}\text {-Sex: } \\
\text { Male } \\
\text { Female }\end{array}$ & $\begin{array}{l}175 \\
225\end{array}$ & $\begin{array}{l}43.8 \\
56.2\end{array}$ \\
\hline $\begin{array}{l}\text { Marital status: } \\
\text { Married } \\
\text { Widow } \\
\text { Divorced }\end{array}$ & $\begin{array}{c}216 \\
165 \\
19\end{array}$ & $\begin{array}{c}53.9 \\
41.3 \\
4.8\end{array}$ \\
\hline $\begin{array}{l}\text {-Educational level: } \\
\text { Illiterate and read and write } \\
\text { Elementary education } \\
\text { Secondary education } \\
\text { University/higher education }\end{array}$ & $\begin{array}{c}201 \\
38 \\
125 \\
36\end{array}$ & $\begin{array}{c}50.1 \\
9.5 \\
31.3 \\
9.1\end{array}$ \\
\hline $\begin{array}{l}\text {-Occupation before retirement: } \\
\text { - Not working (Include house } \\
\text { wife) } \\
\text {-Working }\end{array}$ & $\begin{array}{l}107 \\
293 \\
\end{array}$ & $\begin{array}{l}26.7 \\
73.3 \\
\end{array}$ \\
\hline $\begin{array}{l}\text {-If working, type of work: } \\
\text { Professional work } \\
\text { Craftsmanship } \\
\text { Office work } \\
\text { Free business } \\
\text { Farmer }\end{array}$ & $\begin{array}{l}39 \\
75 \\
56 \\
37 \\
86\end{array}$ & $\begin{array}{l}13.7 \\
25.5 \\
18.8 \\
12.6 \\
29.4\end{array}$ \\
\hline $\begin{array}{l}\text {-Monthly income: } \\
\text { Sufficient and spare from it } \\
\text { Sufficient for the elderly needs } \\
\text { Not sufficient and owed }\end{array}$ & $\begin{array}{c}25 \\
316 \\
59\end{array}$ & $\begin{array}{c}6.3 \\
79.0 \\
14.7 \\
\end{array}$ \\
\hline $\begin{array}{l}\text { - Residence: } \\
\text { Rural } \\
\text { Urban }\end{array}$ & $\begin{array}{l}201 \\
199\end{array}$ & $\begin{array}{l}50.2 \\
49.8\end{array}$ \\
\hline
\end{tabular}


Table (2): Distribution of the studied elderly according to their medical history

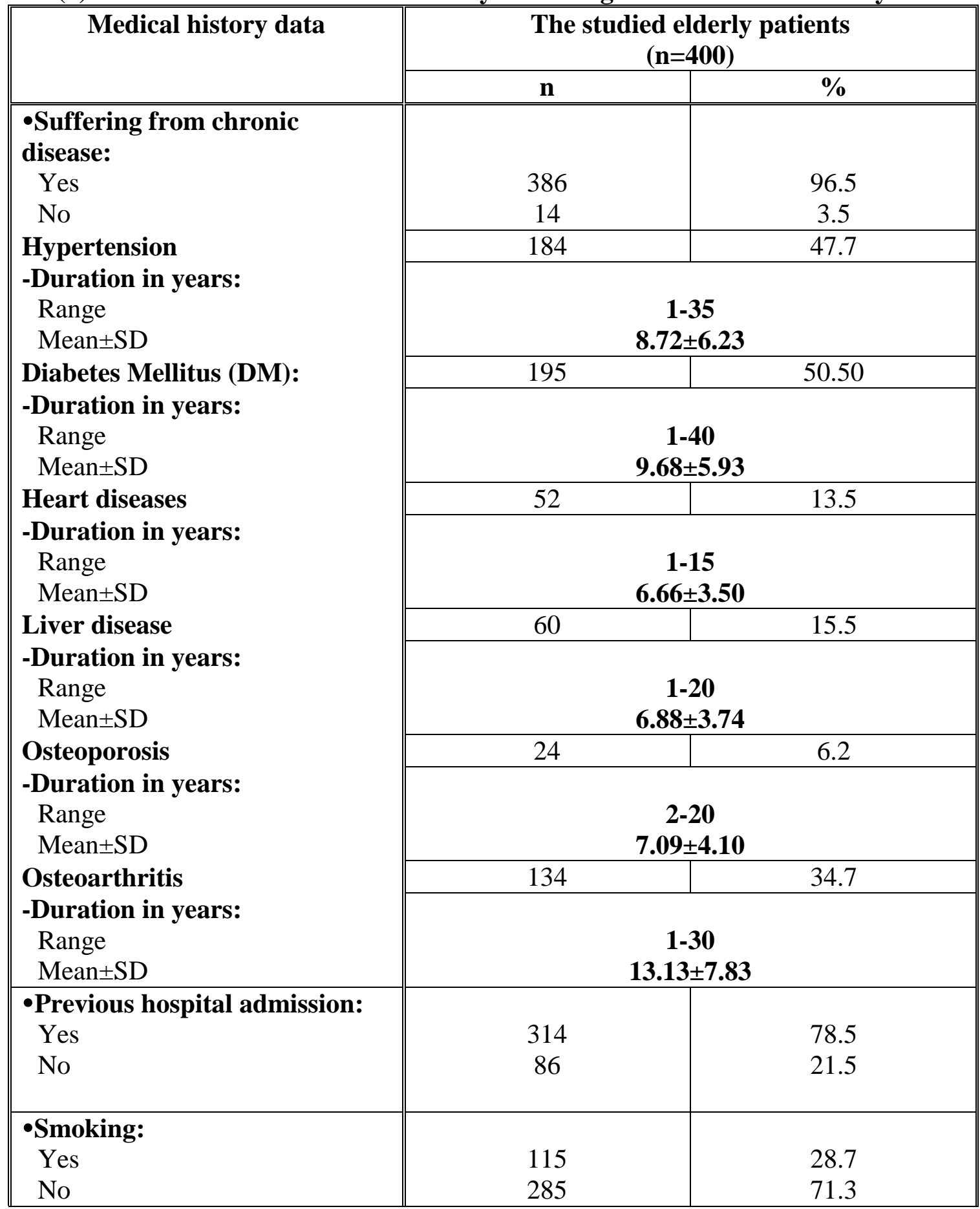


Table (3): Distribution of the studied elderly according to their response to health literacy categories

\begin{tabular}{|l|c|c|c|c|c|c|}
\hline \multirow{2}{*}{ Health Literacy categories } & \multicolumn{5}{|c|}{ Response of the studied elderly patients } \\
(n=400)
\end{tabular}

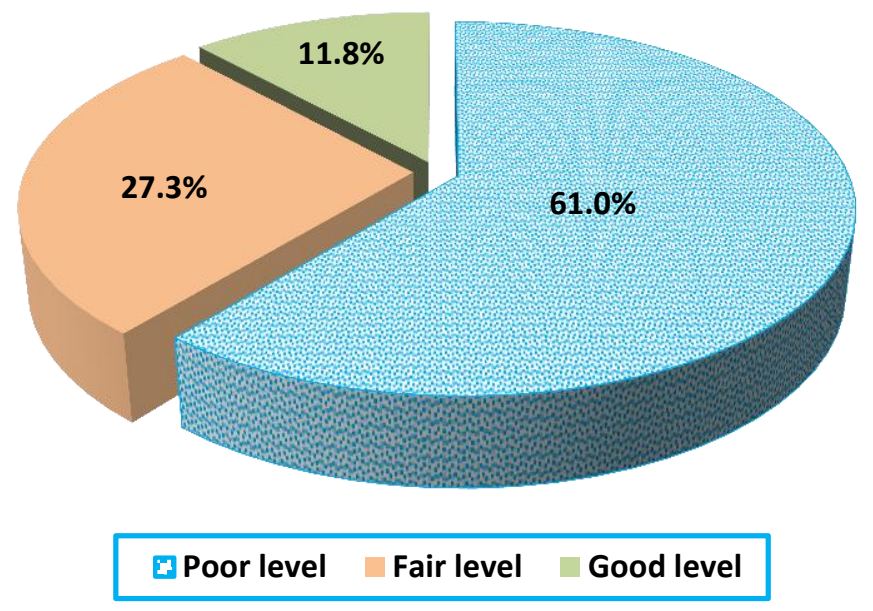

Figure (1): Distribution of the studied elderly according to their total health literacy level 
Table (4): Distribution of the studied elderly according to their total level of adherence to health promoting behaviors dimensions

\begin{tabular}{|c|c|c|c|c|c|c|}
\hline \multirow{3}{*}{$\begin{array}{l}\text { Health promoting } \\
\text { behaviors' dimensions }\end{array}$} & \multicolumn{6}{|c|}{$\begin{array}{l}\text { Level of adherence to health promoting behaviors of the } \\
\text { studied elderly patients } \\
\qquad(\mathrm{n}=400)\end{array}$} \\
\hline & \multicolumn{2}{|c|}{$\begin{array}{c}\text { Low adherence } \\
\text { level }\end{array}$} & \multicolumn{2}{|c|}{$\begin{array}{c}\text { Moderate } \\
\text { adherence level }\end{array}$} & \multicolumn{2}{|c|}{$\begin{array}{c}\text { High } \\
\text { adherence } \\
\text { level }\end{array}$} \\
\hline & $\mathbf{n}$ & $\%$ & $\mathbf{n}$ & $\%$ & $\mathbf{n}$ & $\%$ \\
\hline Health responsibility & 247 & 61.7 & 116 & 29.0 & 37 & 9.3 \\
\hline Physical activity & 367 & 91.7 & 30 & 7.5 & 3 & 0.8 \\
\hline Nutrition & 44 & 11.0 & 262 & 65.5 & 94 & 23.5 \\
\hline Interpersonal relations & 34 & 8.5 & 184 & 46.0 & 182 & 45.5 \\
\hline Rest \& stress management & 230 & 57.5 & 146 & 36.5 & 24 & 6.0 \\
\hline Spiritual growth & 86 & 21.5 & 272 & 68.0 & 42 & 10.5 \\
\hline
\end{tabular}

N.B. Low level of adherence $(25 \%-<50 \%)$, Moderate level of adherence $(50 \%-<$ $75 \%)$, high level of adherence (75\%-100\%) 


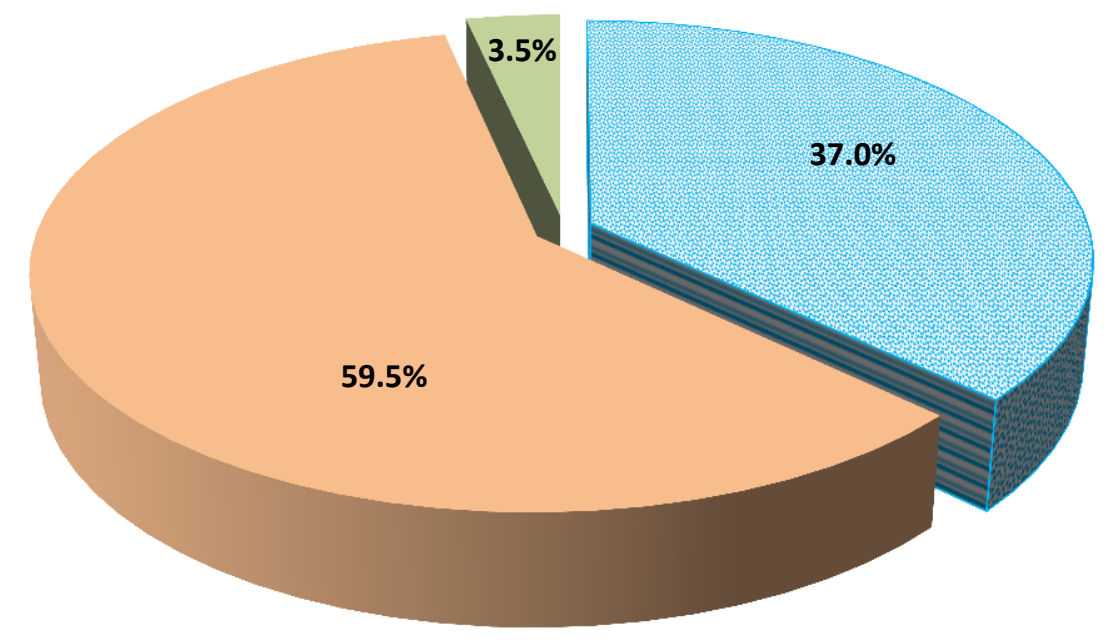

⿴囗十 Low adherence level Moderate adherence level High adherence level

Figure (2): Distribution of the studied elderly according to their level of adherence to health promoting behaviors' dimensions

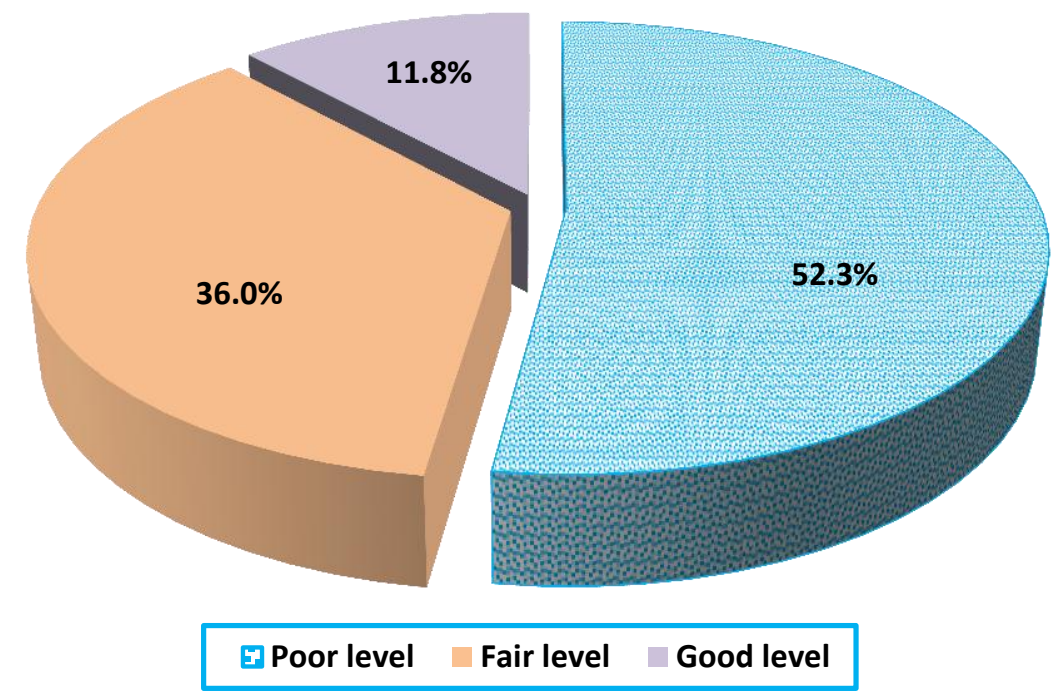

Figure (3): Distribution of the studied elderly according to their total knowledge level regarding basic health issues 
Table (5): Relationship between total knowledge level and both total health literacy level and adherence to health promoting behaviors level among the studied elderly patients

\begin{tabular}{|c|c|c|c|c|c|c|c|c|}
\hline \multirow[t]{3}{*}{ Variables } & \multicolumn{6}{|c|}{$\begin{array}{l}\text { Total knowledge level among the studied } \\
\text { elderly patients } \\
(n=400)\end{array}$} & \multirow{3}{*}{$\chi^{2}$} & \multirow[t]{3}{*}{$\mathbf{P}$} \\
\hline & \multicolumn{2}{|c|}{$\begin{array}{c}\text { Poor level } \\
(n=209)\end{array}$} & \multicolumn{2}{|c|}{$\begin{array}{c}\text { Fair level } \\
(n=144)\end{array}$} & \multicolumn{2}{|c|}{$\begin{array}{c}\text { Good level } \\
(n=47)\end{array}$} & & \\
\hline & $\mathbf{n}$ & $\%$ & $\mathbf{n}$ & $\%$ & $\mathbf{n}$ & $\%$ & & \\
\hline $\begin{array}{l}\text { - Total health } \\
\text { literacy Level: }\end{array}$ & & & & & & & & \\
\hline Poor (244) & 182 & 87.1 & 60 & 41.7 & 2 & 4.3 & 215.109 & $0.0001 *$ \\
\hline Fair (109) & 20 & 9.6 & 72 & 50.0 & 17 & 36.2 & & \\
\hline Good (47) & 7 & 3.3 & 12 & 8.3 & 28 & 59.5 & & \\
\hline $\begin{array}{l}\text {-Total adherence to } \\
\text { health promoting } \\
\text { behaviors level: }\end{array}$ & & & & & & & & \\
\hline Low adherence (148) & 118 & 56.5 & 26 & 18.1 & 4 & 8.5 & 155.145 & $0.0001 *$ \\
\hline $\begin{array}{l}\text { Moderate adherence } \\
\text { (238) }\end{array}$ & 91 & 43.5 & 117 & 81.2 & 30 & 63.8 & & \\
\hline High adherence (14) & 0 & 0 & 1 & 0.7 & 13 & 27.7 & & \\
\hline
\end{tabular}

Table (6): Relationship between total health literacy levels and levels of total adherence to health promoting behaviors among the studied elderly patients

\begin{tabular}{|c|c|c|c|c|c|c|c|c|}
\hline \multirow[t]{3}{*}{ Variables } & \multicolumn{6}{|c|}{$\begin{array}{l}\text { Total health literacy levels among the } \\
\text { studied elderly patients } \\
(n=400)\end{array}$} & \multirow{3}{*}{$\chi^{2}$} & \multirow[t]{3}{*}{$\mathbf{P}$} \\
\hline & \multicolumn{2}{|c|}{$\begin{array}{c}\text { Poor level } \\
(n=244)\end{array}$} & \multicolumn{2}{|c|}{$\begin{array}{c}\text { Fair level } \\
(n=109)\end{array}$} & \multicolumn{2}{|c|}{$\begin{array}{c}\text { Good level } \\
(n=47)\end{array}$} & & \\
\hline & $\mathbf{n}$ & $\%$ & $\mathbf{n}$ & $\%$ & $\mathbf{n}$ & $\%$ & & \\
\hline $\begin{array}{l}\text { - Levels of total } \\
\text { adherence to health } \\
\text { promoting behaviors: } \\
\text { Low adherence (148) }\end{array}$ & 123 & 50.4 & 24 & 22.1 & 1 & 2.2 & 118.911 & $0.0001 *$ \\
\hline $\begin{array}{l}\text { Moderate adherence } \\
\text { (238) }\end{array}$ & 121 & 49.6 & 83 & 76.1 & 34 & 72.3 & & \\
\hline High adherence (14) & 0 & 0 & 2 & 1.8 & 12 & 25.5 & & \\
\hline
\end{tabular}

*Statistically significant $(\mathbf{P}<0.05)$ 


\section{Discussion}

Health literacy is a major international public health concern. It has become an important topic in today's health care environment. It seems reasonable that health literacy would be important when considering an older individuals' health. As the elderly persons number increase all over the world, more consideration given to their healthcare to achieve successful aging. Successful ageing for older adults could be reached through care preventive approach, and improving health literacy is the principle of non-pharmaceutical measures directed to elderly individuals (22-24)

The elderly people largely affected by inadequate health literacy due to agerelated changes such as decline in their cognitive ability that contribute to an older adult's ability to comprehend and/or recall new topics. Moreover, physical impairments such as hearing and vision loss may also contribute to a decreased ability to process health information. In addition, psychosocial factors such as socioeconomic status and coping may negatively influence understanding of the health information $^{(11)}$.

The lack of health-related knowledge and/or skills may serve as a barrier to engagement in healthy behaviors, preventative services as well as chronic disease management. Moreover, inadequate health literacy (HL) is adversely connected with social factors and health behaviors among elderly. It also related with different unwanted outcomes such as poor self-appraised wellbeing and lack of adherence to health promoting behaviors. Inadequate $\mathrm{HL}$ is more prevalent among elderly people that adversely connected with health practices and health risk behaviors among them ${ }^{(11,25,26)}$.

Therefore, the aim of this study was to assess the relation between health literacy and health promoting behaviors of elderly. Health literacy is perceived as one of the most important concepts for modern health promotion activities to be successful. In the declaration arising from the $9^{\text {th }}$ Global Conference of health promotion held in 2016 in Shanghai, health literacy was indicated as a critical determinant of health ${ }^{(27)}$.

The current study found that less than twothirds of the studied elderly had poor health literacy level (figure1). This may be attributed to the mean age of the studied elderly that was $64.45 \pm 5.37$ years (table I) where the health literacy decline as the age increase due to the age related changes which affect the elderly ability to access, understand, appraise and apply health information. Moreover, nowadays most health information has been in written formats which require a high reading, 
calculating, and decision-making skills. These skills require education while in the current study more than half of the studied elderly were illiterates /read and write (table 1). In addition, more than half of the studied elderly reported that, they had never/ rare access to health information, reading of health information, and appraisal of health care (table 5) which may be a contributing factor to the decline in the health literacy level among the studied elderly.

This finding was in the same line with some Egyptian studies. Awad et al., (2018) (28) who conducted a study for assessment of health literacy and health risk behaviors among elderly at Assiut city and Abd AL-Rahman et al., (2014) (29) who studied health literacy prevalence among elderly care givers and its impact on the frequency of elderly hospitalization in Ain Shams. They found that, slightly more than three quarters of the studied sample had low health literacy. These findings highlight the need for more efforts to be directed toward increasing elderly health literacy.

When knowledge and awareness are present, better performance is expected. In this regard, the current study revealed that, slightly more than half of the studied elderly had poor knowledge level regarding the basic health issues (figure3). This may be justified by, the presence of more than two thirds of the studied elderly who had never or rare access to health information. Also, more than one third of them never or rarely understand the health information (table 3). This finding may indicate weakness in health care system in conducting health education sessions for the elderly attendee. This could be attributed to the myth generally believed by health professionals that elderly are unable to understand health information. This highlights the need to direct health professionals to put greater emphasis for conducting health education programs for elderly. This finding was in contrast with an Iranian study conducted by Taheri et al., (2013) ${ }^{(30)}$ who studied the elderly awareness on healthy lifestyle during aging and found that more than two thirds of the studied elderly had excellent knowledge.

In addition, the current study revealed the presence of statistical significant relationship between total knowledge level among the studied elderly patients and their level of total health literacy where more than half of those who gained good level of total knowledge gained also good level of total health literacy (table5). This finding could be used to motivate nurses to conduct health education sessions for elderly as it is worthwhile .This finding was in contrast with an 
Iranian study conducted by Razazi et al., (2018) (31) who studied the relationship between health literacy and knowledge about heart failure with recurrent admission of heart failure patients which revealed that, there is no significant relationship between health literacy and knowledge.

Furthermore, the current study also revealed that, there was statistical significant relationship between total knowledge's levels among the studied elderly patients and their levels of total adherence to health promoting behaviors where those who gained good level of total knowledge were from those who gained either moderate or high level of total adherence to health promoting behaviors (table 6). This finding was in the same line with an Iranian study done by Tawalbeh et al., (2013) (32) who studied the effect of cardiac education on knowledge and adherence to healthy lifestyle which found positive correlation between knowledge and adherence to healthy lifestyle. These finding put emphasis on the importance of knowledge in modifying individual behavior.

Health promoting behaviors is very important for the elderly health, it plays an important role in reducing the morbidity, prevent chronic diseases, improve their quality of life (QOL) and reduce health care costs on the community
(33). In this regard, the current study illustrated that, more than half of the studied elderly had moderate level of adherence to health promoting behaviors (figure2). This finding may be justified by, as the people grow old they have more sense of concern about their health and become more engaged in healthy lifestyle as much as possible in order to maintain independence and self-esteem. In the same time, more than half of the studied elderly in the current study were married which may suggest that couples provide mutual support for each other to be involved in a healthy lifestyle. Also, more than one third of them had secondary education (table I) and aware of the importance of adherence to healthy lifestyle in this age.

This finding was in contrast with an Iranian study conducted by Mofrad et al., (2015) (34) who conducted a study to investigate health promotion behaviors and chronic diseases of aging in the elderly people of Iranshahr which found that, more than half of the studied elderly got the score of inappropriate health promoting behaviors. This discrepancy between the findings may be attributed to the culture variation as well as the living style where in rural Egypt the people prefer to live in extended families where the presence of care givers to the elderly 
people could encourage and help the older ones to follow a healthy lifestyle.

The most important health promoting behaviors for the elderly are health responsibility, physical activity, stress management, nutrition, spiritual growth and interpersonal relations ${ }^{(35)}$. In this regard, this study revealed that, more than two thirds of the studied elderly had low adherence level toward their health responsibility (table 4). This finding may be attributed to the belief of the studied elderly that the changes occur in their bodies is due to aging process which they may consider them normal. Also, their perception about their health, where most of them consider themselves healthy until the onset of disease manifestation. This finding was in agreement with an Egyptian study done by El-Sayed et al., (2015) ${ }^{\text {(36) }}$ who assessed the prevalence and risk factors of obesity among elderly attending geriatric outpatient clinics in Mansoura city which revealed that, nearly two thirds of the participants assume negative responsibility towards their health.

Concerning the studied elderly adherence to physical activity and stress management, the current study revealed that, the majority of them had low adherence level to physical activity as well as about half of them also had low adherence level regarding rest and stress management dimension (table 4). This finding may be attributed to the age related changes such as musculoskeletal, psychological and mood changes which interfere with their ability to perform the physical activities as well as their ability to adapt with the stressful situations. This finding was in agreement with the study done by ElSayed et al., (2015) ${ }^{(36)}$ who found that, more than half of studied elderly didn't participate in any physical activity in the same time stress management was practiced negatively by slightly more than half of the studied elderly.

As regard to the adherence to the proper nutrition dimension, the current study revealed that, more than two thirds of the studied elderly had moderate adherence level (table 4). This may be reasoned by the presence of multiple chronic diseases as the majority of the studied elderly were suffering from chronic diseases (table 2) which impose a nutritional regimen to manage their chronic disease properly. This finding was in contrast with the study done by Sayed et al., (2015) ${ }^{(36)}$ who found that, more than half of the participant consumes unhealthy diet.

Furthermore, the current study revealed that, most of the studied elderly had either moderate or high level of adherence toward the interpersonal relation (table 4). This finding may be justified by presence of more leisure time in the elderly life than previous. So, they tend to spend more time 
with their close friends retrieving their memories and share their feelings and experiences with each other as well as seeking social support. Moreover, more than two- thirds of them had moderate adherence level toward spiritual growth (table 4). This may be attributed to; as the people grow old they have a sense of fear from death and become more involved in the religious practices. This findings was in contrast with El-Sayed et al., (2015) ${ }^{(36)}$ who found that, the interpersonal relations and spiritual growth were practiced negatively by slightly more than half of the studied elderly.

The relation between health outcomes and health literacy (HL) could be shown through health behaviors as the human behavior had a main role in maintaining health and prevention of diseases. The elderly individuals with inadequate HL are less mindful of health behaviors significance $(33,37)$. In this regard, the current study found that, there was a positive relationship between health literacy level and level of adherence to health promoting behaviors (6) as the elderly who had higher levels of health literacy tend to have greater level of adherence to the health promoting behaviors. This finding may be attributed to the fact that health literacy provides the elderly with health information and enable them to apply this health information in order to make judgments and take decisions in everyday life concerning healthcare, disease prevention and health promotion to maintain or improve the quality of life during their life course ${ }^{(38)}$. This result was similar to the finding of some international studies. A Chinese study conducted by $\mathbf{L i}$, et al., (2020) ${ }^{(39)}$ who studied the associations among health-promoting lifestyle, health literacy, and cognitive health in older Chinese and Iranian study conducted by Cherik et al., (2018) ${ }^{(10)}$ who studied the relationship between health literacy and health promoting behaviors in patients with type 2 diabetes. They found that, there was a significant relationship between all dimensions of health promoting behaviors and health literacy.

Finally, this study provides an evidence that, there is a positive link between health literacy and health promoting behaviors, which reflects that health literacy plays an important role in health promotion. Health literacy plays key roles in promoting the elderly people's health and reduction of their medical costs. Therefore, the health literacy must be considered as a factor that promotes the elderly health behaviors, help them to develop a healthy lifestyle, and improve their quality of life.

\section{Conclusion}

Based on the findings of the present study, it can be concluded that, the majority of the 
studied older people had poor level of health literacy, moderate level of adherence to health promoting behaviors as well as poor level of knowledge regarding the basic health issues. In addition, a statistical significant relation was found between health literacy level and level of adherence to health promoting behaviors among the elderly as the poor health literacy level associated with low adherence to the healthy lifestyle.

\section{Recommendations}

Based on the results of the present study the following recommendations were suggested:

- Community health nurses should organize health education programs about health promoting lifestyles and health literacy for older adults to help in improving their overall health.

- Community health nurses should develop health education materials such as booklets and brochures about the health promoting behaviors and the basic health information using plain language and images suitable for the elderly.

- A greater emphasize should be given by the nursing schools to the involvement of health literacy topics in the basic nursing curriculum and continuing education for nursing students to be able to assess the elderly health literacy level.
- Each health facility needs to develop and use health literacy assessment tool that assists in measuring health literacy in order to respond to elderly health needs.

- In-service training programs on health literacy skills need to be developed by health facilities and provided to nurses to improve their abilities in caring with elderly.

- Nurses and health professionals need to improve health literacy in health care settings. They must embed HL in programs, policies, strategic plan and research activities.

- Health literacy should be an essential part of the mission and goals for any health care organization in order to improve its effectiveness in responding to client's needs.

\section{References}

1. World Health Organization (WHO).About Aging and Life Course. 2019 .Available from: https://www. who.int/ageing/about/en.

2. Percentage of Older Persons in Egypt 2018 CAPMAS.2018 .Available from: https://wwww. dailynewssegypt.com /2018/09/29/ percentage-of-olderpersons-in-egypt-6-7-in-2018-capmas/

3. Robnett R, Chop W. Gerontology for the Health Care Professional. $3^{\text {rd }}$ ed. United State of America: Jones and Bartllett Co, 2015;4. 
4. Sweed H, Maemon M. Egypt Ageing Population. Egyptian Journal of Geriatrics and Gerontology.2014; 1(1):1-9.

5. World Health Organization (WHO).Aging and Health.2018.

Available from: https://www. who.int/ news-room/fact-sheets/ detail/ ageingand-health.

6. Zanjani S, Tol A, Mohebbi B, Sadeghi R, Jalyani K,Moradi A. Determinants of Healthy Lifestyle and Its Related Factors among Elderly People. Journal of Education and Health Promotion. 2015; 4(4): 103.

7. Jaul E, Barron J. Age-Related Diseases and Clinical and Public Health Implications for the 85 Years Old and Over Population. Front Public Health Journal. 2017; 5(5):335.

8. Altgeld T, Gesundheit L , Sozialmedizin A, Niedersachsen E, Sinclair J.Healthy and Active Aging. Europe. Europe Health Net Co, 2012; 14-15.

9. World Report on Ageing and Health.2015. Available from: https:// apps.who.int/iris/bitstream/handle/106 65/86468/WHO_FWC_ALC_15.01_e ng.pdf;jsessionid=DF0C9479B737FB 22E3D9074BC7538A67?sequence=1

10. Cherik Sh,Gheibizadeh M, Jahani S, Cheraghian B. The Relationship between Health Literacy and Health Promoting Behaviors in Patients with
Type 2 Diabetes. International Journal of Community Based Nurse Midwifery. 2018; 1(6): 65-75.

11. Chesser A, Woods N, Smothers K, RogersN. Health Literacy and Older Adults. Gerontological and Geriatric Medicine Journal.2016; 15 (2):3-41.

12. Okan $\mathrm{O}$, Bauer $\mathrm{U}$, Zemir D, pinheir $\mathrm{P}$, Sorensen K. International Handbook of Health Literacy in Research, Practice and Policy across Lifespan, Brittian,: Policy Press Co,2019;5-21.

13. KolarT, Kaucic B, Kolnik T. The Role of the Nurse in Improving Health Literacy among Older Adults. Race Originale Journal.2017; 2(16):59-64.

14. Disease Prevention and Health Promotion. National Action Plan to Improve Health Literacy.2012. Available from: https://health.gov/ our-work/health-literacy/nationalaction-plan-improve-health-literacy.

15. Andrew G. Introduction to Epi Info 2002.2004. Available from: http://www .epiinformatics.com/IntroToEpi2002. htm.

16. Emiral O, Aygar $\mathrm{H}$, Isiktekin $\mathrm{B}$, Göktas S, Dagtekin G, Arslantas D etal., Health Literacy Scale European Union -Q16: A Validity and Reliability Study in Turkey. International Research Journal of Medical Science. 2018; 6 (1): 1-7. 
17. Dodson S, Good S, Osborne $\mathrm{H}$. Health Literacy Toolkit for Low- and Middle-Income Countries: A Series of Information Sheets to Empower Communities and Strengthen Health Systems. New Delhi: World Health Organization Regional Office For South-East Asia, 2014;38-47.

18. Hawkins M, Gill S, Batterham R, Elsworth G, Osborne R. The Health Literacy Questionnaire (HLQ) at the Patient-Clinician Interface: A Qualitative Study of What Patients and Clinicians Mean by Their HLQ Scores. Biomedical Central Health Services Research Journal.2017; 1(17):309-321.

19. Ghanbari S. Health Literacy Measure for Adolescents (HELMA).2015. Available from: https://health literacy.bu.edu/documents/ 197/HELM A .pdf

20. Walker S, Sechrist K, Pender N. Health Promotion Model - Instruments to Measure Health Promoting Lifestyle : Health- Promoting Lifestyle Profile [HPLP II] (Adult Version).1995. Available from: http:// hdl.handle. net/2027.42/85349.

21. Dawson B, Trapp R: Reading the Medical Literature: Basic \& Clinical Biostatistics Lange Medical Book. $3^{\text {rd }}$ ed. New York: McGraw - Hill. Medical Publication Division, 2001; 161-314.

22. Malik M, Zaidi R, Hussain A. Health Literacy as a Global Public Health Concern: A Systematic Review, Journal of Pharmacology \& Clinical Research. 2017; 4(2):1-5.

23. Leod S, Musich S, Hawkins $\mathrm{K}$, Douglas G. The Growing Need for Resources to Help Older Adults Manage their Financial and Healthcare Choices, BMC Geriatrics Journal. 2017; 17(1):477-87.

24. WHO. Global Strategy and Action Plan on Ageing and Health. USA: Rose Wiley Co.;4-10.

25. Adams R. Improving Health Outcomes with Better Patient Understanding and Education, Risk Management Health Policy Journal. 2010; 3(3): 61-72.

26. Kobayashi L, Wardle J, Wolf M, Wagner C. Cognitive Function and Health Literacy Decline in a Cohort of Aging English Adults. Journal of General Internal Medicine, 2015; 30(2): 958-964.

27. World Health Organization. $9^{\text {th }}$ Global Conference on Health Promotion Shanghai the Mandate for Health 
Literacy.2016.Available from: https:// www. Who . int / healthpromotion /conferences / 9gchp/healthliteracy/en/.

28. Awad S, Ibrahim H, Hassanen R , Abd-Elaziz S, Assessment of Health Literacy and Health Risk Behaviors among Elderly at Assiut City Egypt. IOSR journal of nursing and health science, 2018; 7(3):59-67.

29. Abdel Rahman T. Health Literacy: Prevalence among Elderly Care Givers and Its Impact on the Frequency of Elderly Hospitalization and Elderly Health Related Quality of Life Advances in Aging Research Journal. 2014; 3(5): 380-387.

30. Taheri M, Mohammadi M, Paknia B, Mohammadbeigi A. Elderly Awareness on Healthy Lifestyle during Aging. Tropical Medicine and Surgery Journal.2013; 5(1):100-139.

31. Razazi R, Mohammad J, Amin A, Taghavi S, Ghadrdoost B, Nader N. The Relationship between Health Literacy and Knowledge about Heart Failure with Recurrent Admission of Heart Failure Patients. Research in Cardiovascular Medicine Journal.2018; 7(3):123-128.

32. Tawalbeh L, Ahmad M. The effect of Cardiac Education on Knowledge and Adherence to Healthy Lifestyle.
Clinical Nursing Research Journal.2014; 23(3):245-258.

33. Jayasinghe $\mathrm{W}$, Harris $\mathrm{F}$, Parker $\mathrm{M}$. The Impact of Health Literacy and Life Style Risk Factors on HealthRelated Quality Of Life of Australian Patients. Health Quality of Life Outcomes Journal. 2016; 14(7):14-68.

34. Mofrad Z, Jahantigh M, Arbabisarjou A. Health Promotion Behaviors and Chronic Diseases of Aging in the Elderly People of Iranshahr, Global Journal Of Health Science, 2016; 8(3): 139-145.

35. Bayati T, Dehghan A, Bonyadi F, Bazrafkan L. Investigating the Effect of Education on Health Literacy and Its Relation to Health-Promoting Behaviors in Health Center, Journal of Education and Health Promotion, 2018; 7(1):107-127.

36. El-Sayed S, Mohamed A, Hatata E, Boughdady A. Prevalence and Risk Factors of Obesity among Elderly Attending Geriatric Outpatient Clinics in Mansoura City, Journal of Education and Practice.2015; 30(6): 222-288.

37. Södergren S, Effects of Health Literacy on Health Status and Health Service Utilization amongst the Elderly. Social Science \& Medicine Journal, 2012; 66(8):1809-1816. 
38. World Health Organization (WHO). Health Literacy Why Health Literacy is Important.2019.

Available from: https://www.euro. who.int/en/health-topics/disease-

prevention/health-literacy/why-healthliteracy-is-important

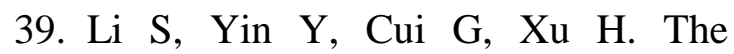
Associations among Health-Promoting Lifestyle, Health Literacy and Cognitive Health in Older Chinese Adults: A Cross-Sectional Study, International Journal of Environmental Research and Public Health. 2020; 17(7): 2263-73. 